\title{
Analysis of differential gene expression of heart failure based on Gene Expression Omnibus database
}

\section{Haifeng Yan}

First Teaching Hospital of Tianjin University of Traditional Chinese Medicine

\section{Xianliang Wang}

First Teaching Hospital of Tianjin University of Traditional Chinese Medicine

\section{Yazhu Hou}

First Teaching Hospital of Tianjin University of Traditional Chinese Medicine

\section{Zhihua Yang}

First Teaching Hospital of Tianjin University of Traditional Chinese Medicine

Jingyuan Mao ( $\nabla$ jymao@126.com )

https://orcid.org/0000-0002-9882-7406

\section{Research article}

Keywords: Differential gene expression, Heart failure, Extracellular matrix, ECM-receptor interaction, IL6

Posted Date: April 20th, 2020

DOl: https://doi.org/10.21203/rs.3.rs-21870/v1

License: (9) This work is licensed under a Creative Commons Attribution 4.0 International License. Read Full License 


\section{Abstract \\ Background}

To screen and identify key genes involved in heart failure and explore underlying molecular mechanisms.

\section{Methods}

The expression profile of GSE26887 was downloaded from Gene Expression Omnibus (GEO), which contained 24 samples, including 19 left ventricle cardiac tissue of heart failure and 5 controls. The differentially expressed genes (DEGs) were obtained and got further analysis by bioinformatics methods. The DEGs and volcano plot were acquired with the use of 'lima' package in ' $R$ ' software and heat map was drawn through the 'heatmap' package. Gene ontology (GO) and pathway analysis of DEGs were performed by means of Database for Annotation, Visualization and Integrated Discovery (DAVID) and Kyoto Encyclopedia of Genes and Genomes (KEGG) online analyses, respectively. The DEGs interaction and network map were constructed through Search Tool for the Retrieval of Interacting Genes (STRING ) database and Cystoscope(v3.6.0)software.

\section{Results}

The transcriptome analysis of left ventricle cardiac tissue showed that 236 genes were differentially expressed between heart failure and control, of which 124 were significantly upregulated $(P<0.01)$ and 101 genes downregulated $(P<0.01)$. GO analysis uncovered that DEGs were enriched in extracellular space, extracellular matrix, extracellular matrix organization, cell adhesion, proteinaceous extracellular matrix and heparin binding. Thus, the function of extracellular matrix is mainly affected. The KEGG pathway enrichment indicated that the DEGs were involved in eight pathways, of these pathways, ECMreceptor interaction, Drug metabolism-cytochrome P450 and Pathogenic Escherichia coli infection are dominant. Protein-protein interaction (PPI) revealed the interactions of 30 protein products encoded of DEGs. Of the 30 protein products, the critical gene, called Interleukin-6 (IL6), was identified with the use of Cystoscope software.

\section{Conclusion}

Extracellular matrix and IL6 play an important role in the development of heart failure. Functional annotation and pathway analysis of these main genes were identified, which provide the basis for insight into the underlying pathogenetic mechanisms and predicting therapeutic targets of heart failure.

\section{Background}


Heart failure is a complex clinical syndrome caused by coronary artery disease, valvular heart diseases, hypertension, diabetes[1], characterized by impaired myocardial systolic performance resulting in the heart fails to provide sufficient blood to meet the needs of peripheral blood tissue. According to the report from 2017 American Heart Association (AHA), heart failure patients have reached 6.5 million in Americans over the age of 20[2]. Worldwide, the mortality of chronic heart failure in patients within 5 years is over $50 \%[3,4]$. Previous study has showed that almost two third patients experienced a readmission, $35.8 \%$ died of the hospitalization[5] and numerous patients will be readmitted once more within a year[6]. This brings about an enormous financial burden on patients, families and society. Despite considerable progress of optimal medical therapy,clinical outcomes are still poor. Thus, it is an imperative issue to offer reasonable guidelines and drug treatment for patients with heart failure.

Currently, a number of studies have revealed the therapeutic targets and signal pathways associated with heart failure, such as mitochondrial function[7], microRNAs[8], Granulocyte colony-stimulating factor[9], Ras homolog gene family, member A Rho kinase (RHOA/ROCK) pathway[10], AMP-activated protein kinase (AMPK) activation[11], Janus kinase/signal transducer and activator of transcription 3 (JAKSTAT3) pathway[12]. The occurrence and development of heart failure are affected by multiple factors (vascular endothelial injury, oxidative stress, inflammatory stimulation, cardiac autophagy, hypertrophy, apoptosis, cardiac remodeling), among them, cardiac remodeling is closely related to the development of heart failure, and inflammatory stimulation and the activation of fibrosis signaling pathways play a vital role in cardiac remodeling $[13,14]$. A variety of cellular and molecular changes involved in the occurrence and development of heart failure, such as cardiomyocytes, fibroblasts, vascular smooth muscle cells, endothelial cells[15], which then cause the changes of intracellular $\mathrm{Ca} 2$ + concentration, apoptosis, extracellular matrix and metabolic[16], and activate corresponding signaling pathways to promote the progression of heart failure. Changes of extracellular matrix exert substantial influence on cardiac remodeling, cell migration, and proliferation. Inflammation, oxidative stimulation and apoptosis can facilitate the pathological reconstruction of extracellular matrix. Therefore, the activation of antiinflammatory, antioxidant and anti-apoptotic signaling pathways[17-21] can protect the heart and improve heart failure. Although progress has been made for some drugs in improving or treating heart failure, the mortality and readmission rate of heart failure are still on the rise, indicating the potential mechanisms have not been adequately addressed by current therapies[2, 22, 23]. In recent years, the expression profiles of heart failure genes have been extensively studied and screened thousands of differential genes by high-throughput sequencing technology. However, sample heterogeneity and different sequencing platforms can lead to differences of expressed mRNA and gene profiles[24]. Although the etiology and mechanisms of heart failure have been extensive studied, the cause remains unclear. Therefore, the differentially genes of heart failure gene chips can be excavated by bioinformatics methods, which provides the basis for further research on the interaction between genes involved in heart failure.

The aim of this study is to elucidate the underlying genes by the bioinformatics method to identify DEGs in left ventricle cardiac tissue of patients with heart failure. With the development of bioinformatics, differential gene expression profile analysis and data mining based on bioinformatics have been 
increasingly used to analyze the potential mechanism of disease[25-27]. Our study provides the basis for further research on the interaction and underlying functions between genes involved in heart failure.

\section{Methods}

\section{Acquisition of DEGs}

The series number GSE26887 was downloaded from the GEO database. GSE26887 was provided by Affymetrix Gene Chips Human Gene 1.0 ST array, using total RNA extracted from 24 samples, including 19 left ventricle cardiac tissue of heart failure and 5 controls. The DEGs were extracted based on the $\mathrm{R} /$ bioconductor lima package. DEGs with fold change $(|\log \mathrm{FC}|>1, P<0.05)$ were obtained for the next step.

\section{Analysis of DEGs}

PPI network was constructed by STRING (http://string-db.org/), a database resource provides the protein interaction information of direct and indirect functional connections in the system biology[28]. In this paper, by setting a confidence score to 0.77 , the web-based STRING database was used to construct PPI network association predictions of upregulation and downregulate on DEGs. It can be clearly seen that the direct and indirect nodes from the protein interaction network and the key genes were identified on DEGs. Bioinformation of the identified DEGs was uncovered by GO and KGEE pathway analysis applying the DAVID platform (version6.8, http://david.ncifcrf.gov/). $P<0.05$ was set as significance cut-off to determine enrichment terms. DEGs were analyzed by network analysis using STRING online software, which can be accessed free of charge via https://string-db.org/. The relationship between protein and protein was constructed by Cystoscope (v3.6.0)software.

\section{Results}

\section{Screening of DEGs}

A total of 236 DEGs were obtained from the GSE26887 as shown in the volcano plot (Fig. 1). and 124 genes were significantly upregulated and 101 genes downregulated $(P$-value $<0.01,|\log \mathrm{FC}|>1)$. The first 10 major differential genes are presented according to the $P$-value $<0.01$ in Table 1 . Fifty DEGs with the lowest $P$-values were displayed on the heat map (Fig. 2). 
Table 1

First 10 major differential genes

\begin{tabular}{|llll|}
\hline Gene & lock & P-value & $\begin{array}{l}\text { Adjusted } \\
\text { P-value }\end{array}$ \\
\hline FAXDC2 & 1.616355629 & $4.74 \mathrm{E}-10$ & $7.18 \mathrm{E}-06$ \\
\hline DSC1 & 2.48063432 & $8.04 \mathrm{E}-10$ & $7.18 \mathrm{E}-06$ \\
\hline FPR1 & -1.162986842 & $1.51 \mathrm{E}-09$ & $7.18 \mathrm{E}-06$ \\
\hline NPPA & 3.320438596 & $1.68 \mathrm{E}-09$ & $7.18 \mathrm{E}-06$ \\
\hline CD163 & -1.788722196 & $1.88 \mathrm{E}-09$ & $7.18 \mathrm{E}-06$ \\
\hline DUSP5 & -1.164211806 & $2.12 \mathrm{E}-09$ & $7.18 \mathrm{E}-06$ \\
\hline GFPT2 & -1.712208299 & $7.43 \mathrm{E}-09$ & $1.89 \mathrm{E}-05$ \\
\hline CFAP61 & 1.30847076 & $1.43 \mathrm{E}-08$ & $3.01 \mathrm{E}-05$ \\
\hline TMEM140 & 1.221705905 & $1.48 \mathrm{E}-08$ & $3.01 \mathrm{E}-05$ \\
\hline HTR4 & 1.13711038 & $6.47 \mathrm{E}-08$ & $9.40 \mathrm{E}-05$ \\
\hline
\end{tabular}

\section{GO enrichment analysis}

The DEGs have uploaded the database of DAVID bioinformatics resources network (https://david.ncifcrf.gov/), which has the function of annotation, visualization and integrated discovery and extracts biological information associated with large gene lists[29, 30]. The identifier was selected as OFFICIAL_GENE_SYMBOL and the list type as Gene List. Other parameters were all fixed. The results showed that DEGs enriched these categories via $\mathrm{GO}$ analysis, containing biological process, cellular component and molecular function and mainly concentrated in the following fields: extracellular space, extracellular matrix, extracellular matrix organization, cell adhesion, extracellular region, proteinaceous extracellular matrix, heparin binding, were demonstrated in Figs. 3 and 4.

\section{KEGG pathway analysis}

DEGs were analyzed using DAVID online website (version6.8, http://david.ncifcrf.gov/) for KEGG pathway analysis and functional annotation, and three key KEGG pathways were identified, including ECM-receptor interaction, Drug metabolism - cytochrome P450, and Pathogenic Escherichia coli infection, HIF-1 signaling pathway and so on, among which ECM-receptor interaction pathway was considered to be the most important one (Fig. 5). 


\section{Analysis Of Protein Network Interaction}

With PPI analysis making use of STRING software, 30 outstanding proteins were identified, among which IL6, CD44, SOCS3, ITGA5, ITGA8, MYC, RPS4Y1 and THBS1 are relatively important. IL 6 was deemed to be the significantly important protein and connected 13 nodes (Figs. 6 and 7).

\section{Discussion}

In this article, the main pathogenesis and biomarkers of heart failure were obtained by screening the DEGs of clinical heart failure expression profile GSE26887 and analyzing the GO function, KEGG pathway enrichment and PPI. The occurrence of heart failure is the result of multi-factors and genes. Therefore, the exploration of the molecular mechanism of heart failure is very important for the occurrence and development of heart failure. The target genes of heart failure have been widely predicted by microarray and the high-throughput sequencing technology, most research has focused on animal experiments for heart failure, and the present study was based on isolated left ventricular myocardial tissue from patients with clinical heart failure, through bioinformatics method to analyze the raw data and identify 236 DEGs. Further information of 236 DEGs was mined based on functions enrichment and signaling pathways, respectively.

This study is to explore the underlying mechanism of action on patients with heart failure. We analyzed the DEGs between patients with heart failure and control by multiple bioinformatics methods including enrichment, KEGG analysis and PPI analysis. According to GEO database, we analyzed the chip GSE26887 making use of R software package, and the DEGs 236 were screened out. PPI analysis showed that IL6, CD44 and SOCS3 genes were key factors for patients with heart failure. A pleiotropic cytokine, IL6, could activate immune cells to protect the host from damage in the short term, however, it became pathogenic to the host in a condition of remaining long-term activation. Chronically elevated IL6 levels result in chronic inflammation and fibrotic disorders for the heart tissue[31]. Studies had shown that elevated serum IL6 levels may be a potential prognostic predictor associated with heart disease, such as heart failure, myocardial infarction, and angina[32-35]. CD44 is a multifunctional transmembrane glycoprotein, which interacts with hyaluronic acid to mediate the migration and proliferation of endothelial cells, macrophages, fibroblasts and other cell types. Meanwhile, it was involved in the stimulation of

Tumor necrosis factora/Nuclear-factor-kappa-B (TNFa/NFkB) signaling pathway to promote the production of inflammation and development of cardiac fibrosis[36-38], causing the remodeling of extracellular matrix. Excessive remodeling of the extracellular matrix was likely to result in heart failure. Therefore, CD44 may be considered as a novel potential therapeutic target for the treatment of heart failure. Another gene, SOCS3, is one of the negative regulators of gp130/JAK/STAT3 signaling pathway, indicating that SOCS3 is closely related to STAT3. Activation of STAT3 signaling pathway is one of the important mechanisms of myocardial hypertrophy, and myocardial remodeling is a compensation method adopted by the body under the condition of overload anterior and posterior of cardiomyocytes, 
which is one of the important mechanisms of heart failure. However, negative feedback regulation of SOCS3 slows down the development of heart failure by inhibiting the overexpression of STAT3. In addition, IL6 can also reduce the expression of SOCS3 by activating STAT3[39, 40], therefore, SOCS3 may be a new potential target for the treatment of heart failure. According to the above discussion,IL6ICD 44 and SOCS3 have a bearing on the remodeling of the extracellular matrix, which act as markers of heart failure to provide a reference basis for the early prevention and treatment of heart failure.

Further analysis of the DEGs revealed that the function was mainly involved in extracellular space, extracellular matrix, extracellular matrix organization by GO enrichment analysis. Extracellular matrix alterations are closely related to cardiac remodeling, which play a pivotal role in the development and evolution of heart failure[41]. IL6, CD44 and SOCS3 can impact the alterations of the extracellular matrix, so they are crucial factors leading to heart failure. KEGG pathway analysis showed the major role of ECMreceptor interaction, drug metabolism - cytochrome P450 and pathogenic Escherichia coli infection pathways in heart failure. Studies have indicated that extracellular matrix is considered as an important role in cardiac remodeling. CD44 is a cell-surface receptor of extracellular matrix proteins, which may serve as an underlying target for inhibiting extracellular matrix remodeling and slowing down the development of heart failure[36]. Other pathways are cytochrome P450 and pathogenic Escherichia coli infection associated with heart failure, among which cytochrome P450 is a multigene superfamily of enzymes that plays an important role for progression and prognosis of heart failure[42], such as cardiac CYP2A, CYP1B, CYP2B and CYP2E mRNA levels, which are related to cytochrome P450, usually increase in heart failure[43]. Moreover, pathogenic Escherichia coli infection is also associated with the progression of heart failure in patients, which can impair tight junctions and perturbs intestinal barrier function[44], possibly leading to intestinal flora disorders. Growing evidence shows that dysbiosis of gut microbiota has an underlying connection with heart failure [45-47], which can contribute to the body inflammation that accelerates the deterioration of heart failure. Therefore, gut microbiota can be considered as potential therapeutic targets for further research on the treatment of heart failure. Through the above analysis of the major genes and pathways of heart failure, it can be seen that inflammation and the alterations extracellular matrix play a major role in the progression of heart failure. Further research is needed to bring insight into the specific mechanisms of heart failure.

\section{Conclusion}

In this study, the mining of clinical specimens is more conducive to the analysis of the mechanism of heart failure. Potential molecules and mechanisms were observed linked to heart failure. Extracellular matrix, ECM-receptor interaction, IL6, CD44 and SOCS3 play a major role by analyzing expression profile of GSE26887 involved in left ventricle cardiac tissue of heart failure.

\section{Declarations}

\section{Acknowledgements}


We appreciate all those who helped us in this research.

\section{Authors' contributions}

Jingyuan Mao contributed to study concept and design. Haifeng Yan drafted the manuscript. Xianliang Wang acquired data and contributed to the analysis and interpretation of data. Yazhu hou and Zhihua Yang critically revised the manuscript and contributed to statistical analysis. Haifeng Yan is the guarantor of this work, and takes responsibility for the accuracy of the data analysis. All authors have approved the final version of the manuscript.

\section{Funding}

No funding was received for this work.

\section{Availability of data and materials}

The chip data analyzed in this study be obtained from corresponding author.

\section{Consent for publication}

Not applicable.

\section{Competing interests}

The authors declare that they have no competing interests.

\section{Author details}

Haifeng Yan, Email: 1972855747@qq.com.

Xianliang Wang, Email: xlwang1981@126.com.

Yazhu Hou, Email: mreleven@163.com.

Zhihua Yang, Email: 2499214290@qq.com. 
Jingyuan Mao, Emali: jymao@126.com.

\section{References}

1. He J, Ogden LG, Bazzano LA, Vupputuri S, Loria C, Whelton PK. Risk factors for congestive heart failure in us men and women: Nhanes i epidemiologic follow-up study. Arch Intern Med. 2001;161(7):996-1002.

2. Benjamin EJ, Blaha MJ, Chiuve SE, Cushman M, Das SR, Deo R, de Ferranti SD, Floyd J, Fornage M, Gillespie C, et al. Heart disease and stroke statistics-2017 update: A report from the american heart association. Circulation. 2017;135(10):e146-603.

3. Cowie MR, Wood DA, Coats AJ, Thompson SG, Suresh V, Poole-Wilson PA, Sutton GC. Survival of patients with a new diagnosis of heart failure: A population based study. Heart. 2000;83(5):505-10.

4. Mosterd A, Cost B, Hoes AW, de Bruijne MC, Deckers JW, Hofman A, Grobbee DE. The prognosis of heart failure in the general population: The rotterdam study. Eur Heart J. 2001;22(15):1318-27.

5. Ziaeian B, Fonarow GC. The prevention of hospital readmissions in heart failure. Prog Cardiovasc Dis. 2016;58(4):379-85.

6. Swami J, Korytkowski M. The futile cycle of hospital readmission in patients with diabetes. J Diabetes Complications. 2017;31(8):1252-53.

7. Brown DA, Perry JB, Allen ME, Sabbah HN, Stauffer BL, Shaikh SR, Cleland JG, Colucci WS, Butler J, Voors AA, et al. Expert consensus document: Mitochondrial function as a therapeutic target in heart failure. Nat Rev Cardiol. 2017;14(4):238-50.

8. Vegter EL, van der Meer P, de Windt LJ, Pinto YM, Voors AA. Micrornas in heart failure: From biomarker to target for therapy. Eur J Heart Fail. 2016;18(5):457-68.

9. D'Amario D, Leone AM, Borovac JA, Cannata F, Siracusano A, Niccoli G, Crea F. Granulocyte colonystimulating factor for the treatment of cardiovascular diseases: An update with a critical appraisal. Pharmacol Res. 2018;127:67-76.

10. Brownfield DG, Venugopalan G, Lo A, Mori H, Tanner K, Fletcher DA, Bissell MJ. Patterned collagen fibers orient branching mammary epithelium through distinct signaling modules. Curr Biol. 2013;23(8):703-9.

11. Li X, Liu J, Lu Q, Ren D, Sun X, Rousselle T, Tan Y, Li J. Ampk: A therapeutic target of heart failure-not only metabolism regulation. Biosci Rep. 2019;39(1).

12. Pang LZ, Ju AC, Zheng XJ, Li F, Song YF, Zhao Y, Gu YF, Chen FL, Liu CH, Qi J, et al. Yiqifumai powder injection attenuates coronary artery ligation-induced myocardial remodeling and heart failure through modulating mapks signaling pathway. J Ethnopharmacol. 2017;202:67-77.

13. Bacmeister L, Schwarzl M, Warnke S, Stoffers B, Blankenberg S, Westermann D, Lindner D. Inflammation and fibrosis in murine models of heart failure. Basic Res Cardiol. 2019;114(3):19. 
14. Frangogiannis NG. The immune system and cardiac repair. Pharmacol Res. 2008;58(2):88-111.

15. Bernardo BC, Weeks KL, Pretorius L, McMullen JR. Molecular distinction between physiological and pathological cardiac hypertrophy: Experimental findings and therapeutic strategies. Pharmacol Ther. 2010;128(1):191-227.

16. Tham YK, Bernardo BC, Ooi JY, Weeks KL, McMullen JR. Pathophysiology of cardiac hypertrophy and heart failure: Signaling pathways and novel therapeutic targets. Arch Toxicol. 2015;89(9):1401-38.

17. Handa P, Tateya S, Rizzo NO, Cheng AM, Morgan-Stevenson V, Han CY, Clowes AW, Daum G, O'Brien KD, Schwartz MW, et al. Reduced vascular nitric oxide-cgmp signaling contributes to adipose tissue inflammation during high-fat feeding. Arterioscler Thromb Vasc Biol. 2011;31(12):2827-35.

18. Matsui T, Li L, Wu JC, Cook SA, Nagoshi T, Picard MH, Liao R, Rosenzweig A. Phenotypic spectrum caused by transgenic overexpression of activated akt in the heart. J Biol Chem. 2002;277(25):22896-901.

19. He S, Wang X, Zhong Y, Tang L, Zhang Y, Ling Y, Tan Z, Yang P, Chen A. Hesperetin post-treatment prevents rat cardiomyocytes from hypoxia/reoxygenation injury in vitro via activating pi3k/akt signaling pathway. Biomed Pharmacother. 2017;91:1106-12.

20. Kawaguchi M, Takahashi M, Hata T, Kashima Y, Usui F, Morimoto H, Izawa A, Takahashi Y, Masumoto J, Koyama J, et al. Inflammasome activation of cardiac fibroblasts is essential for myocardial ischemia/reperfusion injury. Circulation. 2011;123(6):594-604.

21. Chen X, Wang R, Chen W, Lai L, Li Z. Decoy receptor-3 regulates inflammation and apoptosis via pi3k/akt signaling pathway in coronary heart disease. Exp Ther Med. 2019;17(4):2614-22.

22. Wright JS, Wall HK, Ritchey MD. Million hearts 2022: Small steps are needed for cardiovascular disease prevention. JAMA. 2018;320(18):1857-58.

23. Metra M, Teerlink JR. Heart failure. The Lancet. 2017;390(10106):1981-95.

24. Li Z, Wang Q, Chen G, Li X, Yang Q, Du Z, Ren M, Song Y, Zhang G. Integration of gene expression profile data to screen and verify hub genes involved in osteoarthritis. Biomed Res Int. 2018;2018:9482726.

25. Yang G, Chen S, Ma A, Lu J, Wang T. Identification of the difference in the pathogenesis in heart failure arising from different etiologies using a microarray dataset. Clinics. 2017;72(10):600-08.

26. Altara R, Zouein FA, Brandao RD, Bajestani SN, Cataliotti A, Booz GW. In silico analysis of differential gene expression in three common rat models of diastolic dysfunction. Front Cardiovasc Med. 2018;5:11.

27. Yao S, Liu T. Analysis of differential gene expression caused by cervical intraepithelial neoplasia based on geo database. Oncol Lett. 2018;15(6):8319-24.

28. Szklarczyk D, Franceschini A, Kuhn M, Simonovic M, Roth A, Minguez P, Doerks T, Stark M, Muller J, Bork P, et al. The string database in 2011: Functional interaction networks of proteins, globally integrated and scored. Nucleic Acids Res. 2011;39(Database issue):D561-8. 
29. Huang DW, Sherman BT, Tan Q, Kir J, Liu D, Bryant D, Guo Y, Stephens R, Baseler MW, Lane HC, et al. David bioinformatics resources: Expanded annotation database and novel algorithms to better extract biology from large gene lists. Nucleic Acids Res. 2007;35(Web Server issue):W169-75.

30. Dennis G Jr, Sherman BT, Hosack DA, Yang J, Gao W, Lane HC, Lempicki RA. David: Database for annotation, visualization, and integrated discovery. Genome Biol. 2003;4(5):P3.

31. Fontes JA, Rose NR, Cihakova D. The varying faces of il-6: From cardiac protection to cardiac failure. Cytokine. 2015;74(1):62-8.

32. Lindmark E, Diderholm E, Wallentin L, Siegbahn AJJtJotAMA. Relationship between interleukin 6 and mortality in patients with unstable coronary artery disease. 2001;286(17):2107-13.

33. Ikeda U, Ohkawa F, Seino Y, Yamamoto K, Hidaka Y, Kasahara T, Kawai T, Shimada K. Serum interleukin 6 levels become elevated in acute myocardial infarction. J Mol Cell Cardiol. 1992;24(6):579-84.

34. Torre-Amione G, Kapadia S, Benedict C, Oral H, Young JB, Mann DL. Proinflammatory cytokine levels in patients with depressed left ventricular ejection fraction: A report from the studies of left ventricular dysfunction (solvd). J Am Coll Cardiol. 1996;27(5):1201-6.

35. Tsutamoto T, Hisanaga T, Wada A, Maeda K, Ohnishi M, Fukai D, Mabuchi N, Sawaki M, Kinoshita M. Interleukin-6 spillover in the peripheral circulation increases with the severity of heart failure, and the high plasma level of interleukin-6 is an important prognostic predictor in patients with congestive heart failure. J Am Coll Cardiol. 1998;31(2):391-98.

36. Suleiman M, Abdulrahman N, Yalcin H, Mraiche F. The role of $c d 44$, hyaluronan and nhe1 in cardiac remodeling. Life Sci. 2018;209:197-201.

37. Yang LW, Qin DZ, James E, McKallip RJ, Wang NP, Zhang WW, Zheng RH, Han QH, Zhao ZQ. Cd44 deficiency in mice protects the heart against angiotensin ii-induced cardiac fibrosis. Shock. 2019;51(3):372-80.

38. Kuwahara G, Hashimoto T, Tsuneki M, Yamamoto K, Assi R, Foster TR, Hanisch JJ, Bai H, Hu H, Protack $\mathrm{CD}$, et al. $\mathrm{Cd} 44$ promotes inflammation and extracellular matrix production during arteriovenous fistula maturation. Arterioscler Thromb Vasc Biol. 2017;37(6):1147-56.

39. Desai A, Jung MY, Olivera A, Gilfillan AM, Prussin C, Kirshenbaum AS, Beaven MA, Metcalfe DD. II-6 promotes an increase in human mast cell numbers and reactivity through suppression of suppressor of cytokine signaling 3. J Allergy Clin Immunol. 2016;137(6):1863-71. e6.

40. Gao J, Guo Y, Chen Y, Zhou J, Liu Y, Su P. Adeno-associated virus 9-mediated rna interference targeting socs3 alleviates diastolic heart failure in rats. Gene. 2019;697:11-8.

41. Weber KT, Sun Y, Bhattacharya SK, Ahokas RA, Gerling IC. Myofibroblast-mediated mechanisms of pathological remodelling of the heart. Nat Rev Cardiol. 2013;10(1):15-26.

42. Imig JD, Hammock BD. Soluble epoxide hydrolase as a therapeutic target for cardiovascular diseases. Nat Rev Drug Discov. 2009;8(10):794-805.

43. Aspromonte N, Monitillo F, Puzzovivo A, Valle R, Caldarola P, lacoviello M. Modulation of cardiac cytochrome p450 in patients with heart failure. Expert Opin Drug Metab Toxicol. 2014;10(3):327-39. 
44. Shifflett DE, Clayburgh DR, Koutsouris A, Turner JR, Hecht GA. Enteropathogenic e. Coli disrupts tight junction barrier function and structure in vivo. Lab Invest. 2005;85(10):1308-24.

45. Cui X, Ye L, Li J, Jin L, Wang W, Li S, Bao M, Wu S, Li L, Geng B, et al. Metagenomic and metabolomic analyses unveil dysbiosis of gut microbiota in chronic heart failure patients. Sci Rep. 2018;8(1):635.

46. Hayashi T, Yamashita T, Watanabe H, Kami K, Yoshida N, Tabata T, Emoto T, Sasaki N, Mizoguchi T, Irino $\mathrm{Y}$, et al. Gut microbiome and plasma microbiome-related metabolites in patients with decompensated and compensated heart failure. Circ J. 2018;83(1):182-92.

47. Nagatomo $Y$, Tang WH. Intersections between microbiome and heart failure: Revisiting the gut hypothesis. J Card Fail. 2015;21(12):973-80.

\section{Figures}




\section{Volcano}

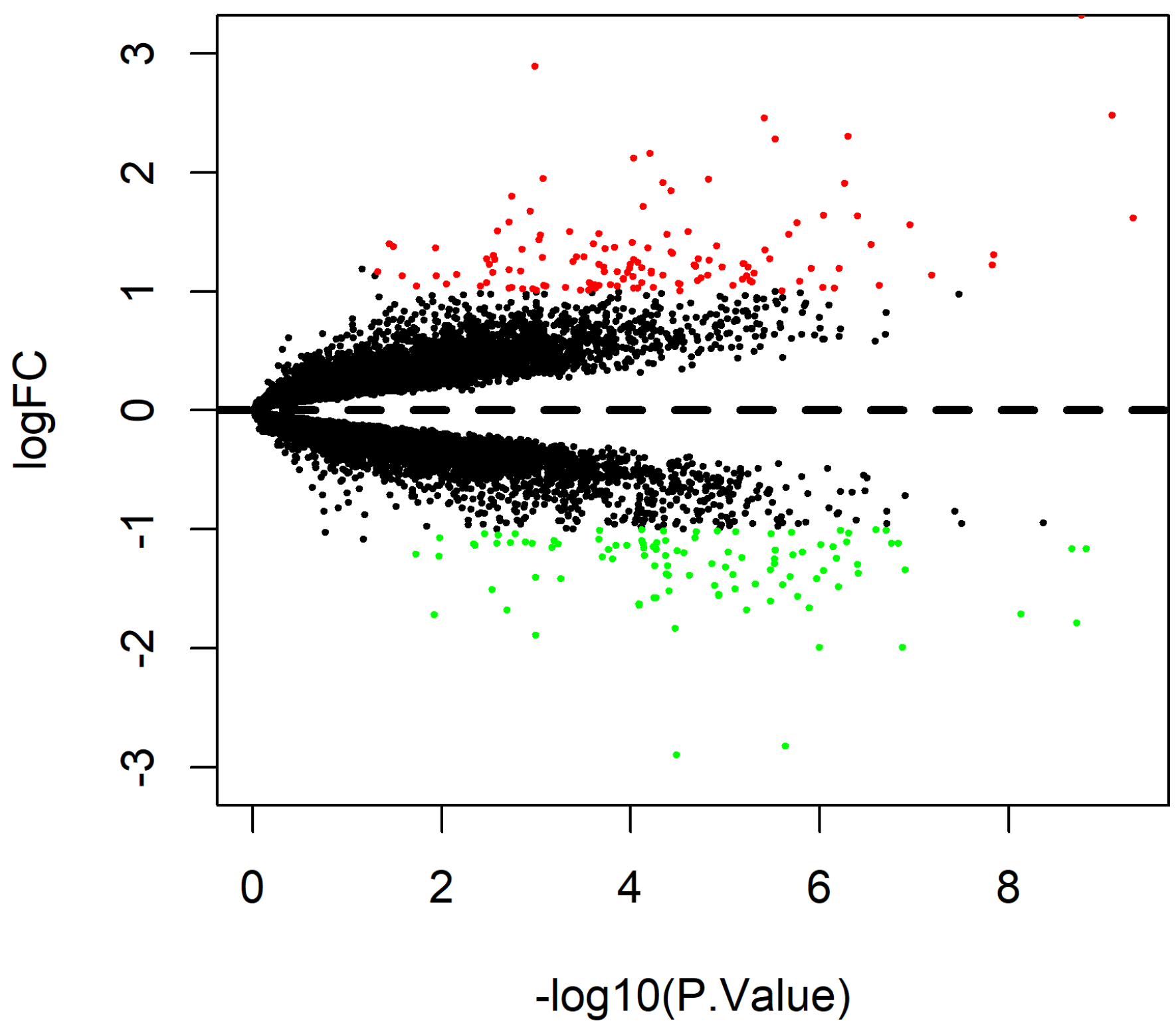

Figure 1

Volcano Plot of DEGs. Red spots indicate upregulated genes; green means downregulated genes. $X$ axis revealed the P-value; and $Y$ axis expressed as fold change of DEGs. 


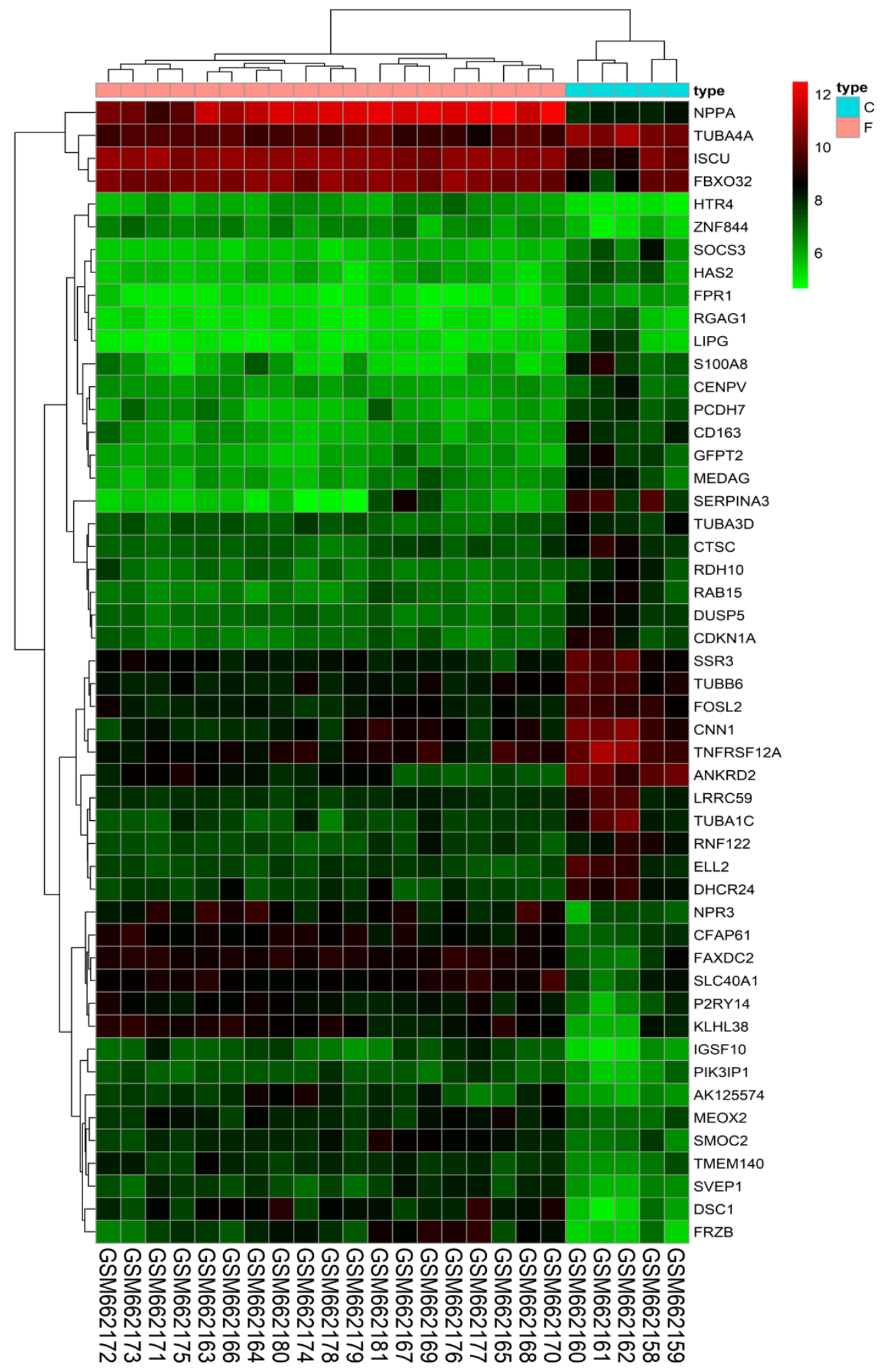

Figure 2

The first 50 DEGs were analyzed in the heat map. The rows represent samples and the columns represent genes. The red represents upregulated genes, the green represents downregulated genes (C represents control groups, F represents heart failure groups). 8, 6, 10 and 12 illustrate the gene expression level. 


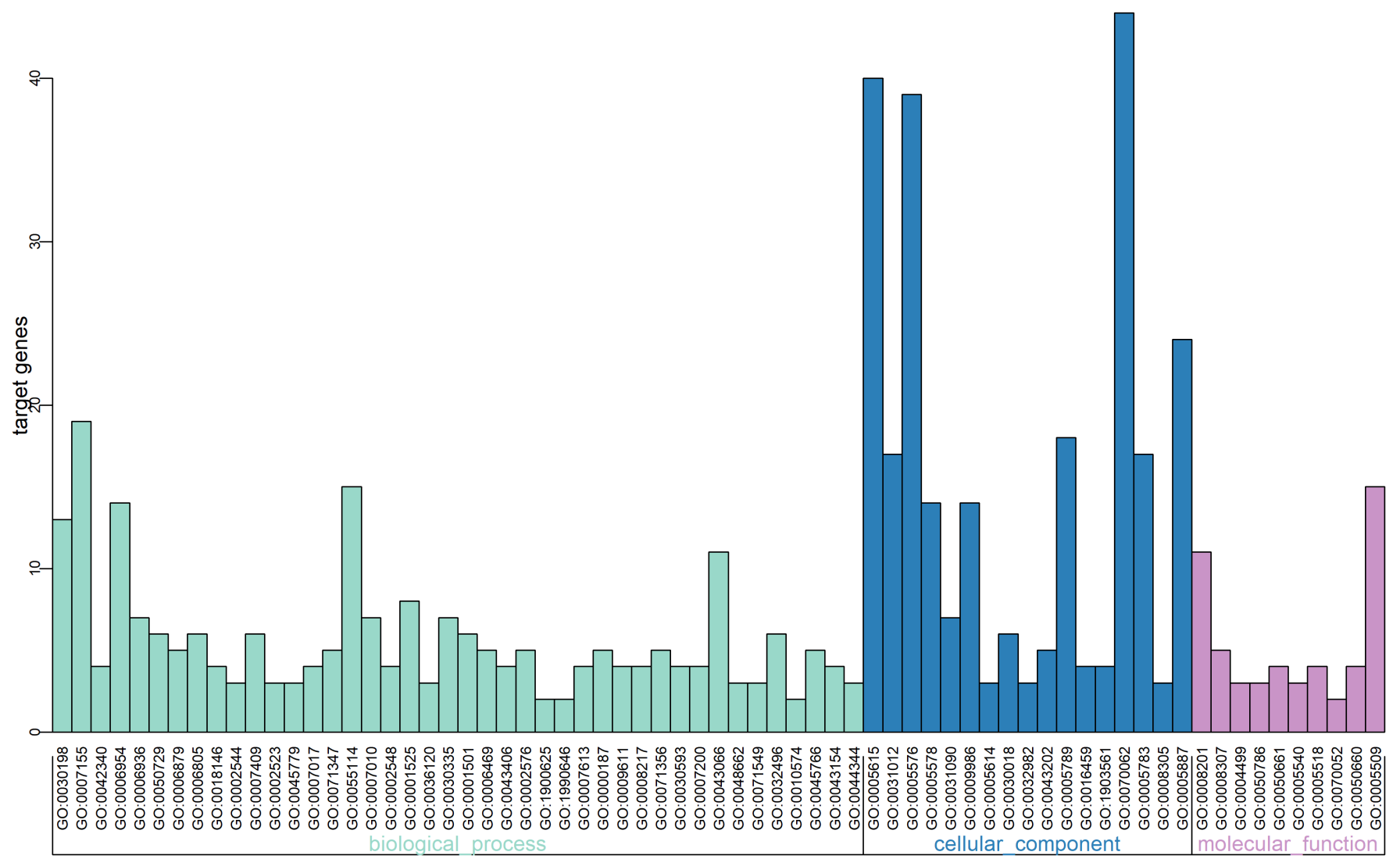

Figure 3

GO analysis of DEGs involved in three groups. Different colors correspond to distinct GO categories. 


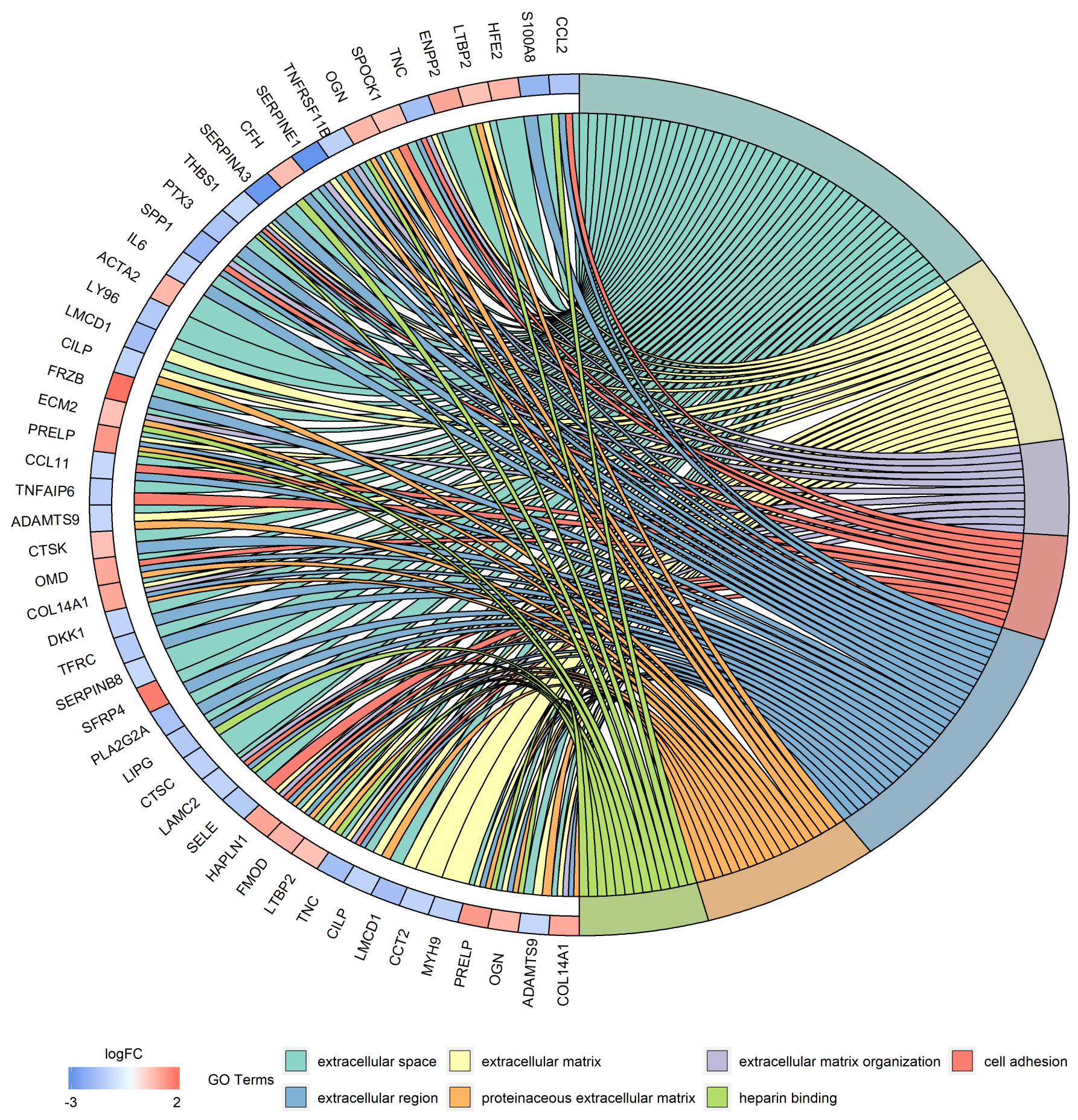

Figure 4

The first 50 DEGs enriched seven GO terms. The red represents upregulated genes, the blue represents downregulated genes. 


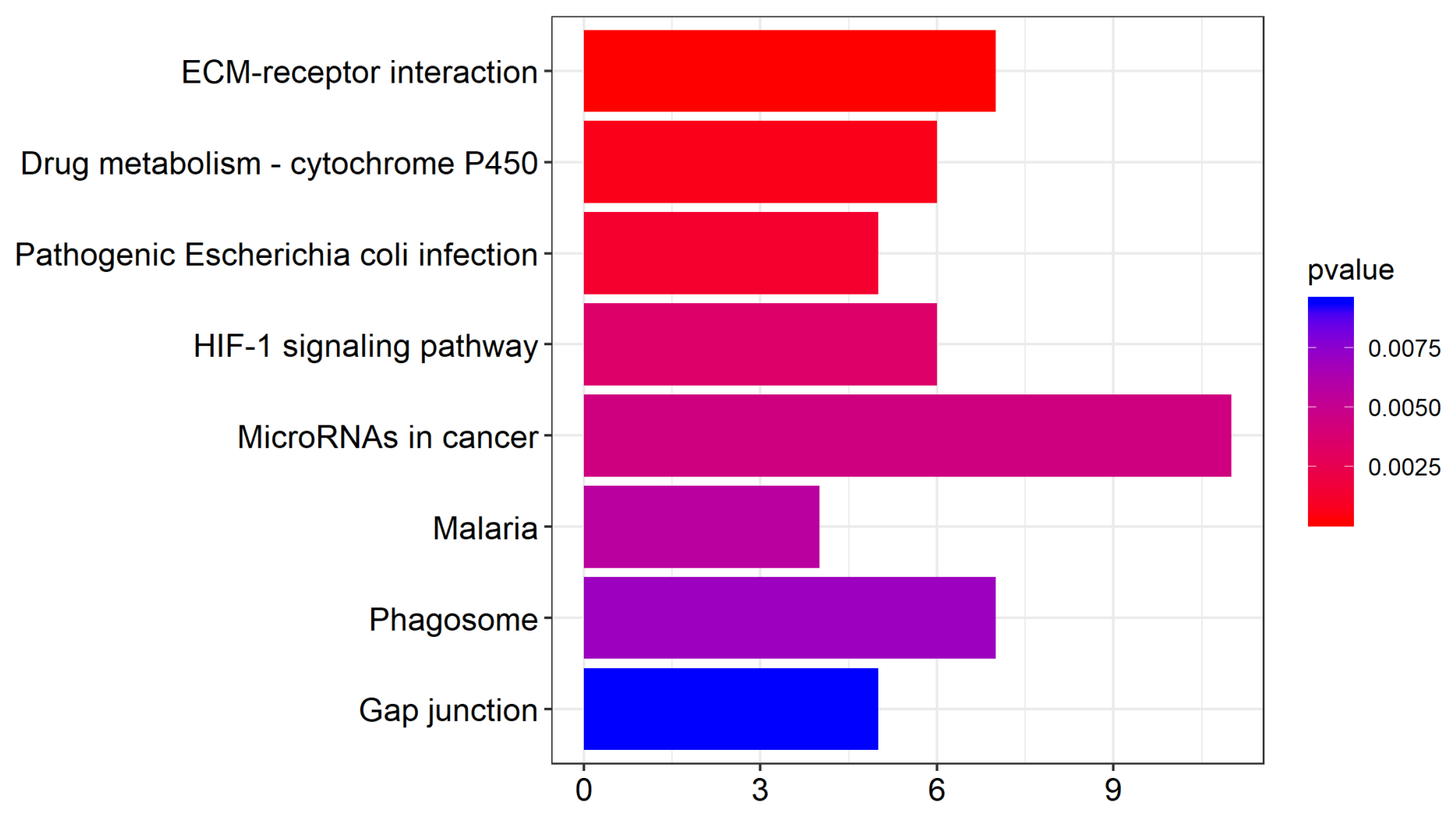

\section{Figure 5}

The color represents different P-value degree. The smaller the-value the more meaningful the pathway.

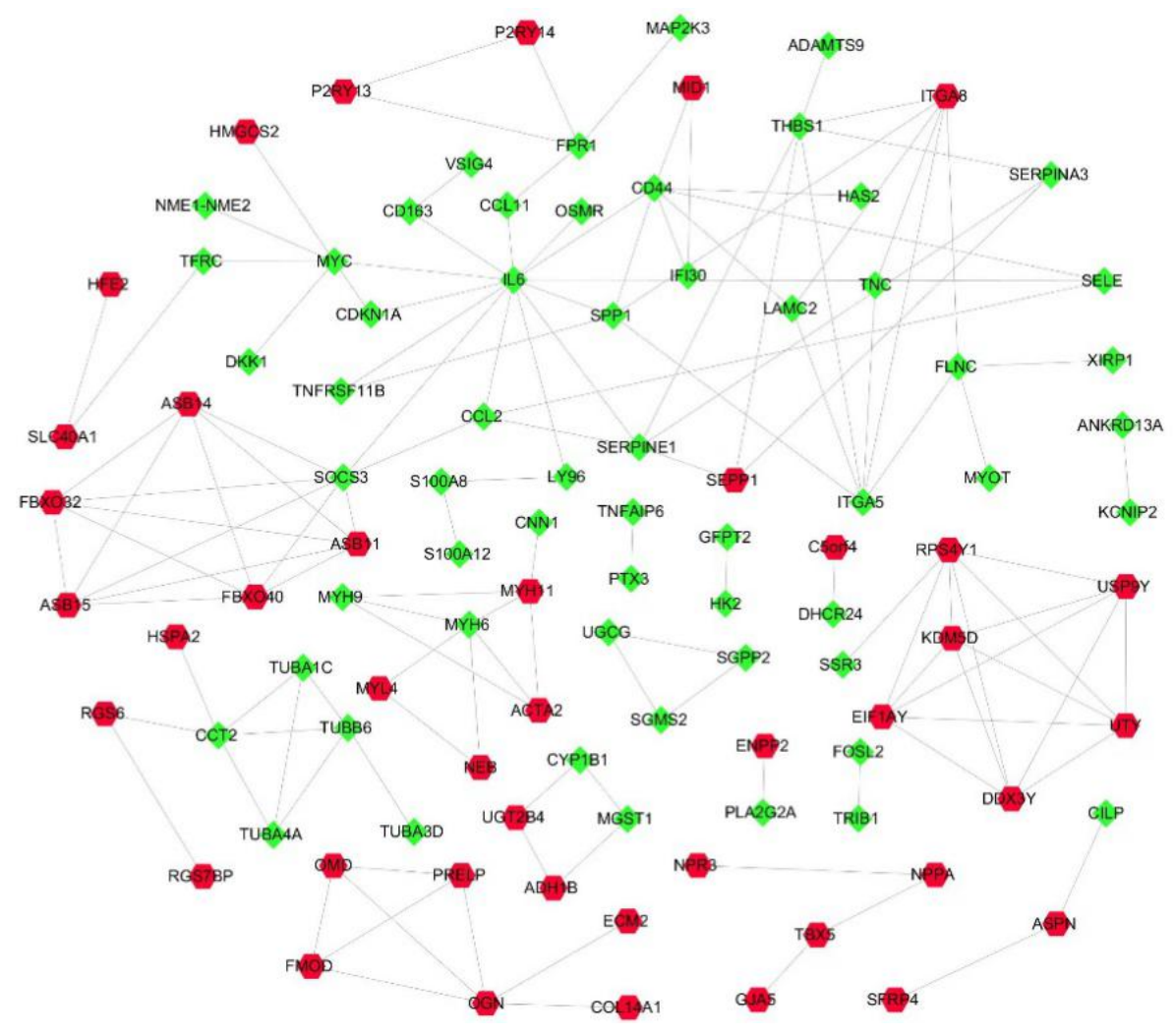


Figure 6

PPI diagram. Rhombus and hexagon represent the gene, and lines represent the interaction between the genes. The red indicates upregulated genes; the green represents downregulated genes.

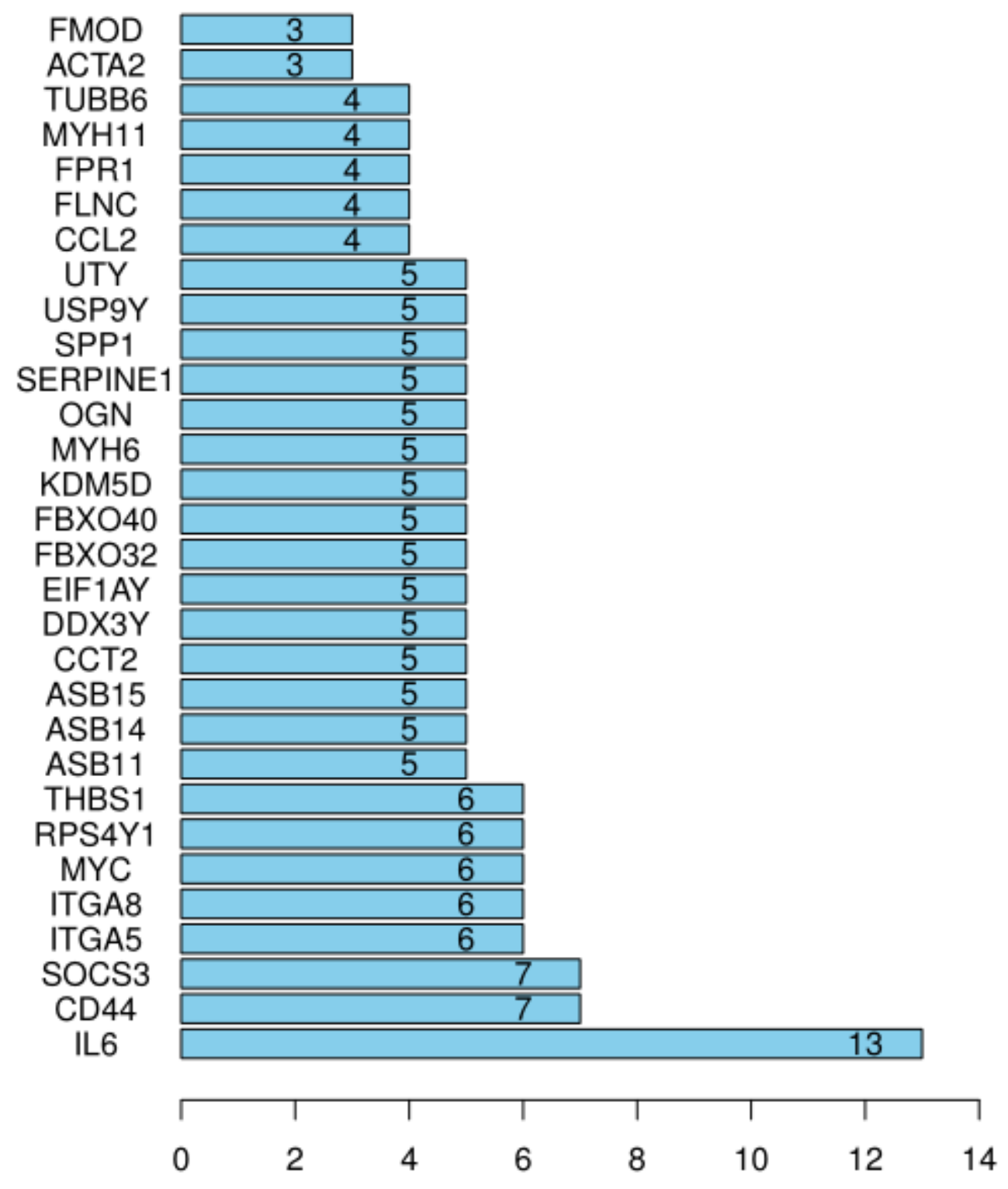

Figure 7

The key proteins histogram. The y-axis represents the name of the first 30 genes, the $x$-axis represents the number of key genes. 